\title{
Online Appendix: The Ecosystem Impacts of Severe Warming
}

By Robert Mendelsohn, lain C. Prentice, Oswald Schmitz, Benjamin Stocker, Robert Buchkowski, and Benjamin Dawson

The analysis relies on the IPCC emission scenario RCP8.5 which postulates a rapid increase in anthropogenic greenhouse gas emissions for over a hundred years and a resulting radiative forcing of $8.5 \mathrm{~W} / \mathrm{m}^{2}$ by year 2100 . Greenhouse gas emissions fall thereafter which eventually stabilizes concentrations. Radiative forcing levels off at $\sim 12 \mathrm{~W} / \mathrm{m}^{2}$ by 2250 . We then use this emission scenario in four CMIP5 climate models: IPSL-CM5A-LR, MPI-ESM-LR, CCSM4, and HadGEM2 to predict climate from 2005 through 2300. These climate scenarios drive the LPX-Bern Global Dynamic Vegetation Model.

The climate model predictions of global mean temperature over time are shown in Figure 1. Temperatures follow an $\mathrm{S}$ shape, rapidly increasing over the $21^{\text {st }}$ century and then rising more slowly as greenhouse gas concentrations stabilize. By 2300, the temperature increase relative to preindustrial levels is $12^{\circ} \mathrm{C}$ for IPSL, $11^{\circ} \mathrm{C}$ for HadGEM2, $10^{\circ} \mathrm{C}$ for MPI, and $9^{\circ} \mathrm{C}$ for CCSM4.

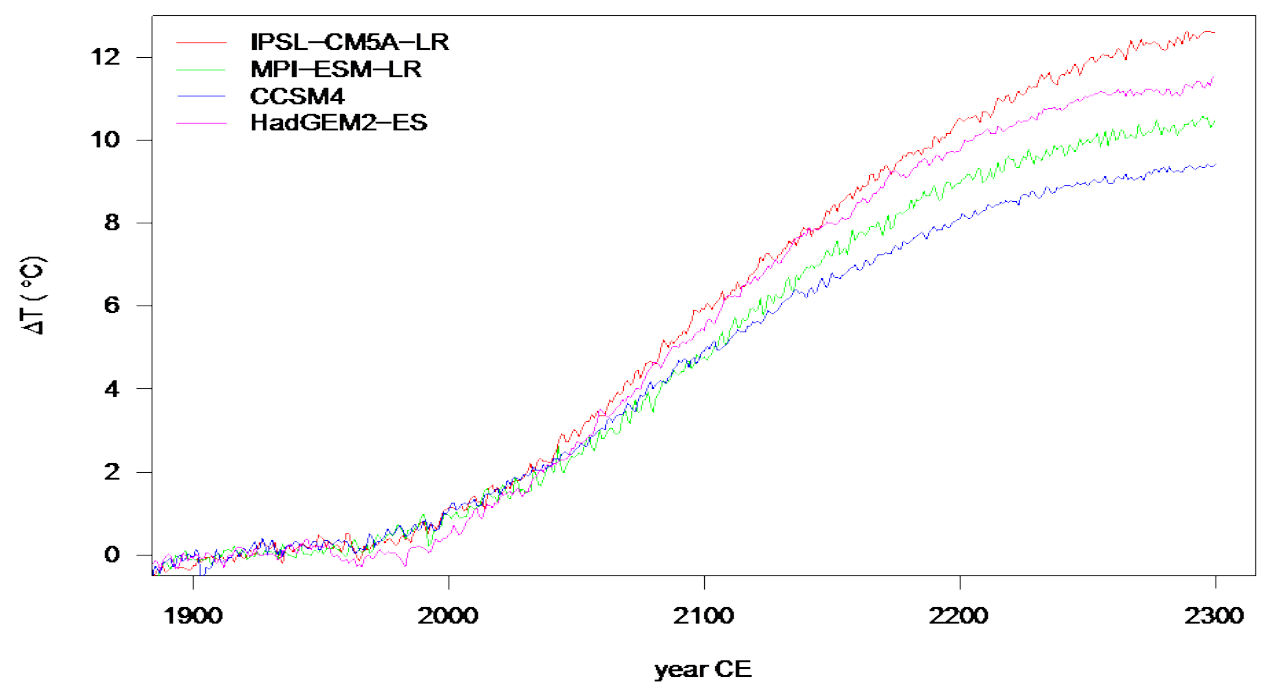

Figure 1 Temperature change over time

The resulting change in biome area can be seen in Figure 2. The distribution of current biomes is presented in panel a. For example the dark green area represents tropical forest which is evident in the Amazon region in South America stretching into Central America and the 
Caribbean, the moist tropical region of Africa stretching from Madagascar across central Africa to coastal West Africa, and in Asia stretching from the Pacific island countries of Indonesia, Philippines and Malaysia into southeast Asia.
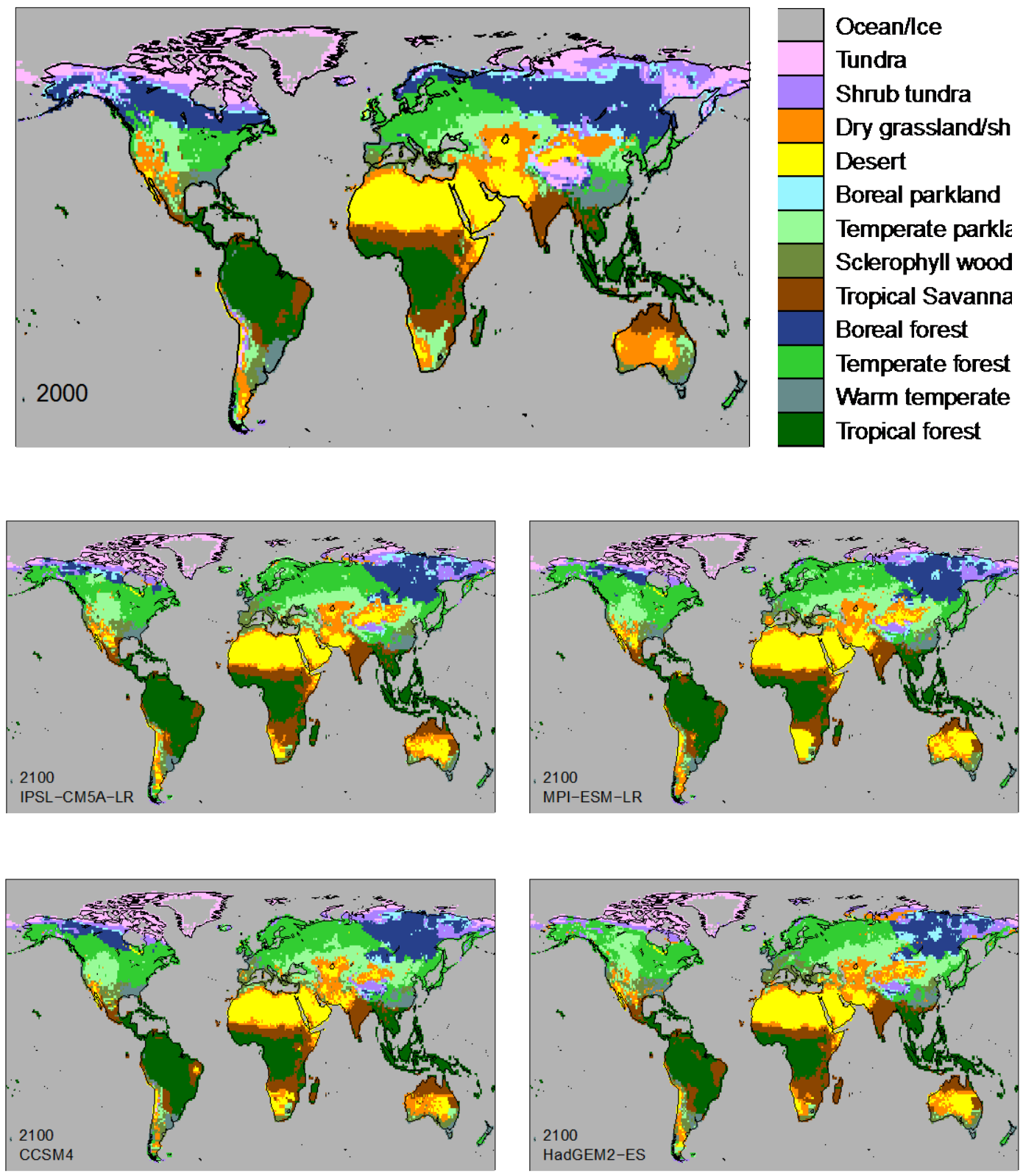

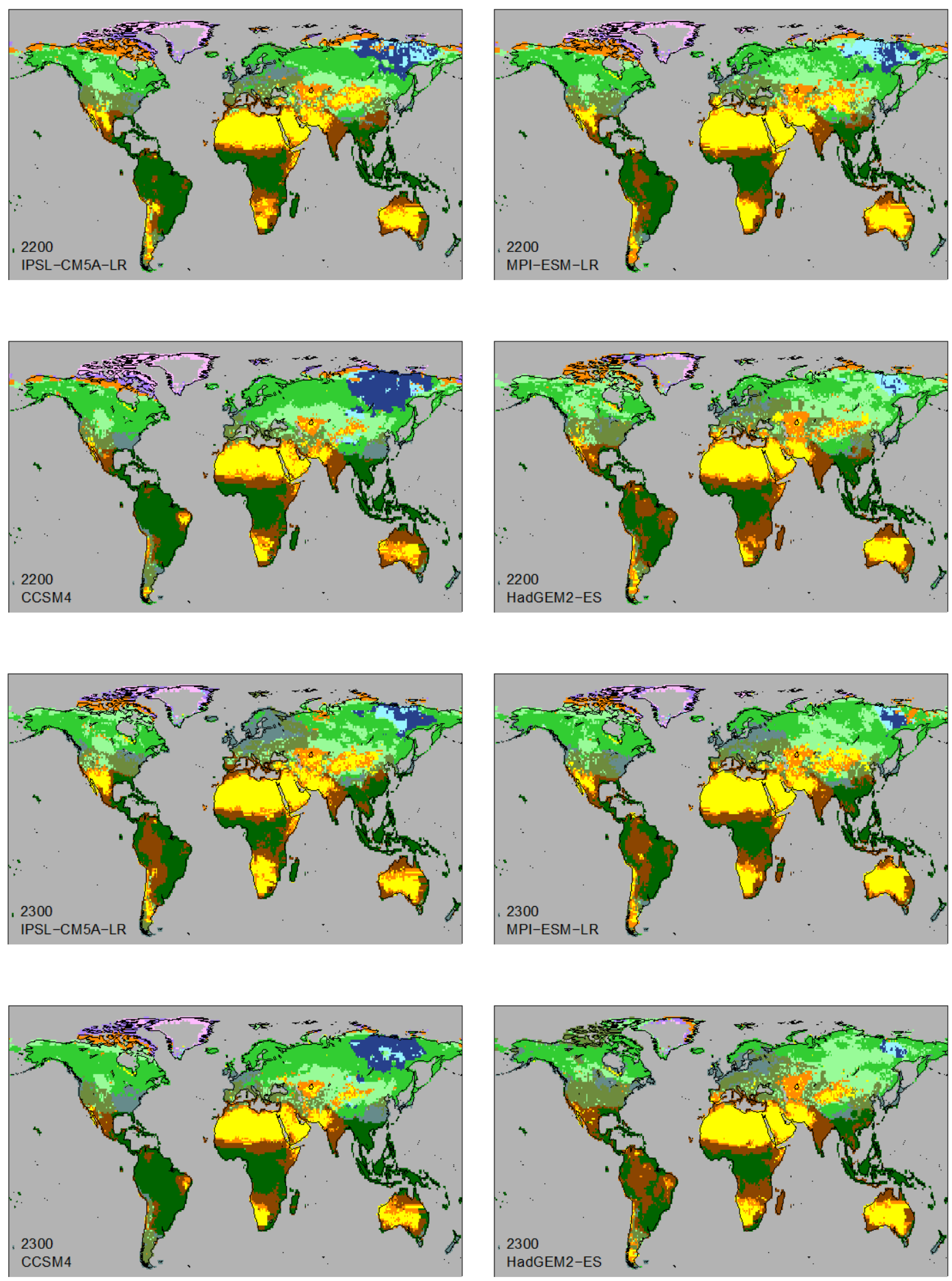

Figure 2 Biome Maps by Year and Climate Model 
The remainder of Figure 2 displays the distribution of biomes each subsequent century $(2100,2200$, and 2300) for all four climate models. The remaining panels illustrate how biomes shift as a result of climate change. There is a noticeable expansion of temperate and tropical forests, generally shifting northwards at the expense of biomes at the northern margins of available land (boreal forests and boreal parkland). This expansion continues through 2300. The boreal forest (blue) and boreal parkland (light blue) shrinks, eventually disappearing in North America. Only evergreen forests remain somewhat stable although even these forests move across space. By 2300, there is also evidence of forest break up. Some of the tropical forest in the Amazon and in Africa turns to tropical savanna. Some of the temperate forest in North America and Europe turns into sclerophyll woodland. The direction of change is similar across climate scenarios but the extent of change varies for each scenario. For example, the smallest amount of forest breakup happens in the milder CCSM4 scenario whereas the most forest breakup occurs in the HadGEM scenario.

The overall area of each forest biome is graphed against global temperature in Figure 3 for each climate scenario. The area of temperate forest has a hill-shaped relationship with global temperature, maximizing at about $6^{\circ} \mathrm{C}$. The area of tropical forest area is also hill-shaped with respect to temperature but with a maximum at about $8^{\circ}-10^{\circ} \mathrm{C}$. In contrast, the size of the boreal forest shrinks immediately with any warming and disappears in North America at high temperatures.

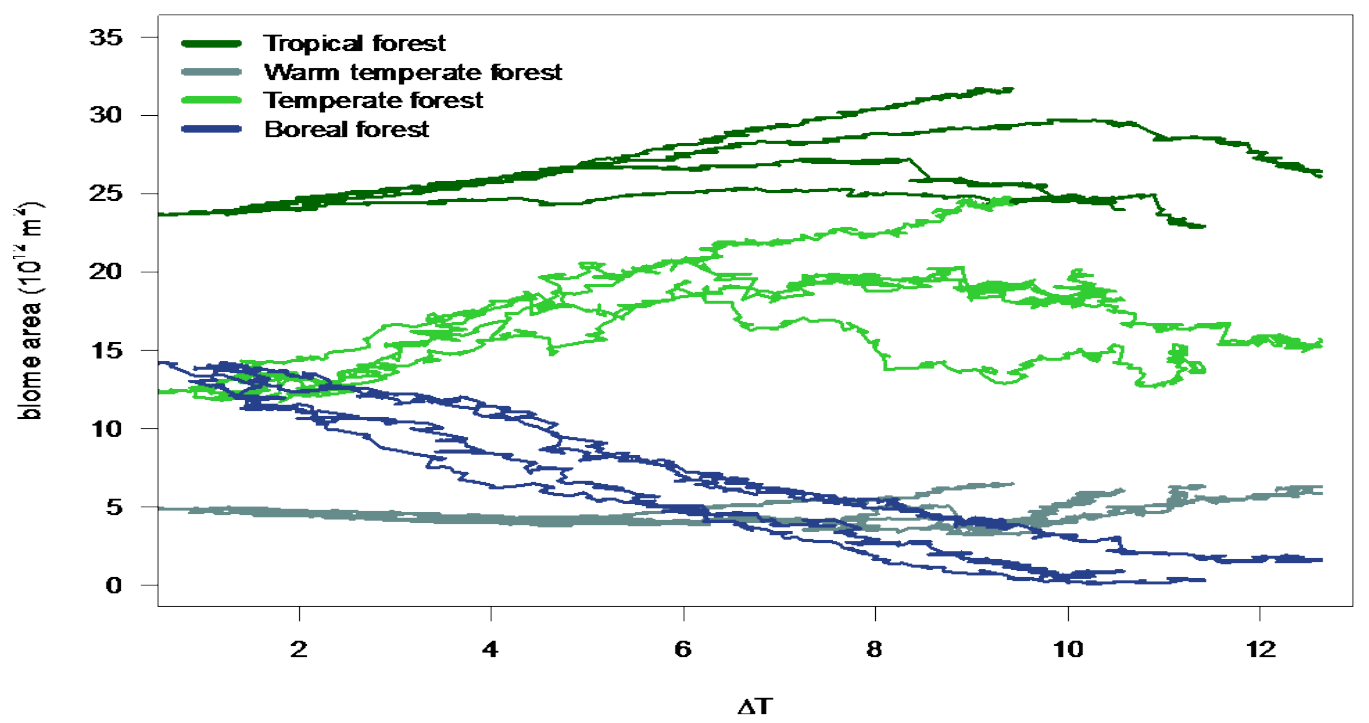

Figure 3 Area of Forest Biome versus Global Temperature 
There are also some shifts in the other biomes evident in Figure 2. Shrub tundra and tundra shrink across all three centuries. The remaining effects vary by climate projection. Overall grassland area tends to remains relatively stable but there is some expansion of grassland in the northern hemisphere and contraction of grassland in the southern hemisphere. Deserts tend to expand about $20 \%$ over the first two centuries mostly in the southern hemisphere and then stabilize.

In addition to these movements of biomes, the productivity of most of the biomes increases. Figure 4 depicts an S shaped growth of NPP over time for each forest biome. NPP rises steadily for each forest biome through 2150 .

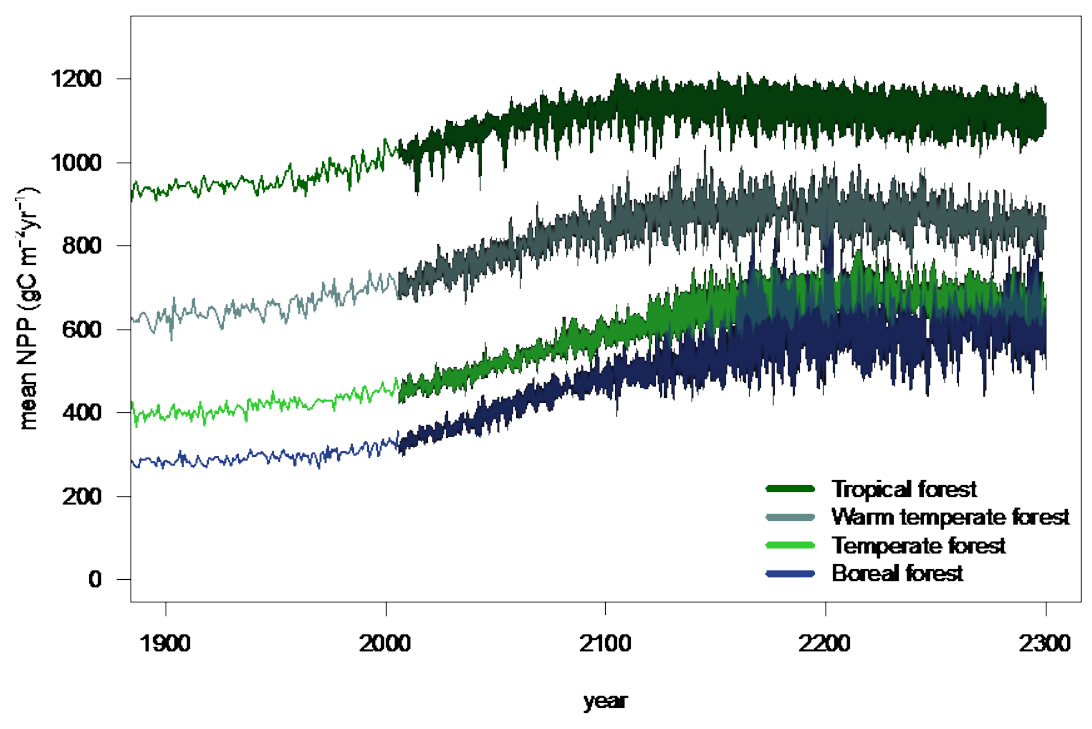

Figure 4 NPP by forest biome over time

As shown in Figure 5, the woodland and parkland biomes also exhibit an S shaped growth of NPP over time. NPP rises through 2150 for woodland sclerophyll, temperature parkland, and boreal parkland and then stabilizes. In contrast, the NPP of tropical savannah, dry grassland, and shrub tundra remain stable over time. 


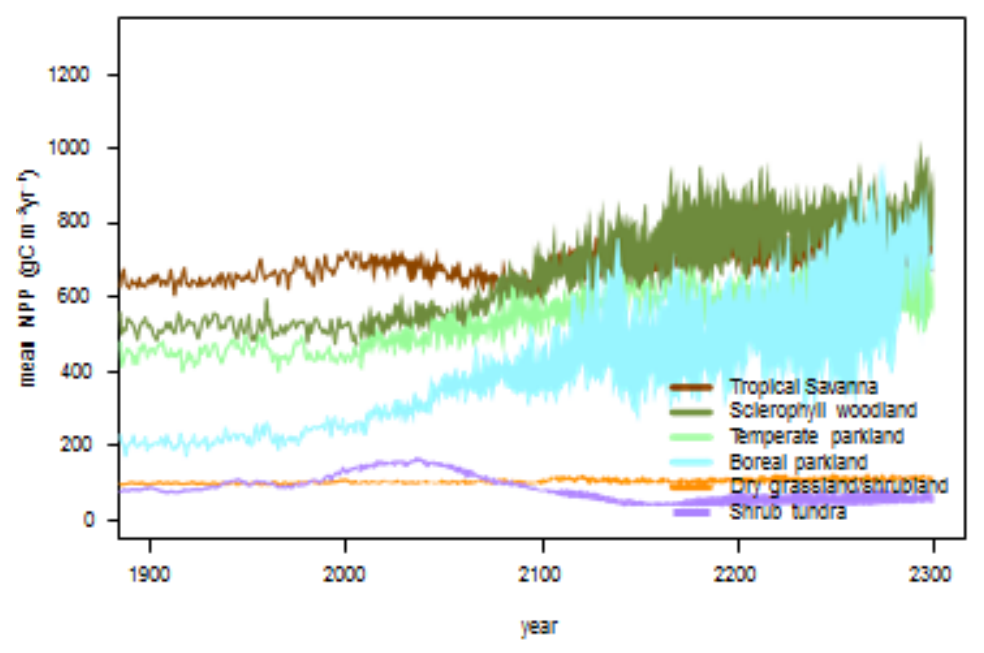

Figure 5: NPP by nonforest biomes over time

Overall, the changes in NPP predicted by the ecological model do not necessarily lead to parallel changes in biome area. The NPP increase of tropical and temperate forest and temperate woodland does lead to an expansion of territory. But the ecological model predicts cold biomes such as boreal forest will shrink even though productivity is rising in this biome. Biome territory depends on competition with other biomes. So as warming permits more productive systems to expand into cooler territory, the biomes already there can only compete if they are as productive as the invaders.

The increased productivity of the forest, woodland, and park vegetation implies more food for animals and hence larger potential animal populations in these biomes per hectare. In contrast, the stable NPP in the remaining biomes suggest that they will continue to support the population levels observed today per hectare.

Initially, from 1900 through 2000 aggregate biomass falls as a result of deforestation (Figure 6). Deforestation slows in the $21^{\text {st }}$ century so that future biomass loss is largely due to climate change. Starting with 2010, global warming is likely to change the aggregate amount of biomass in terrestrial ecosystems. However, the four climate projections lead to four very different projections of biomass change. These aggregate changes in biomass are largely forced by predicted changes in the total area of forest. HadGEM predicts that biomass rises over time, MPI predicts biomass holds steady until 2150 and then declines, and both IPSL and CCSM4 predict biomass will fall through 2200 and then stabilize. 


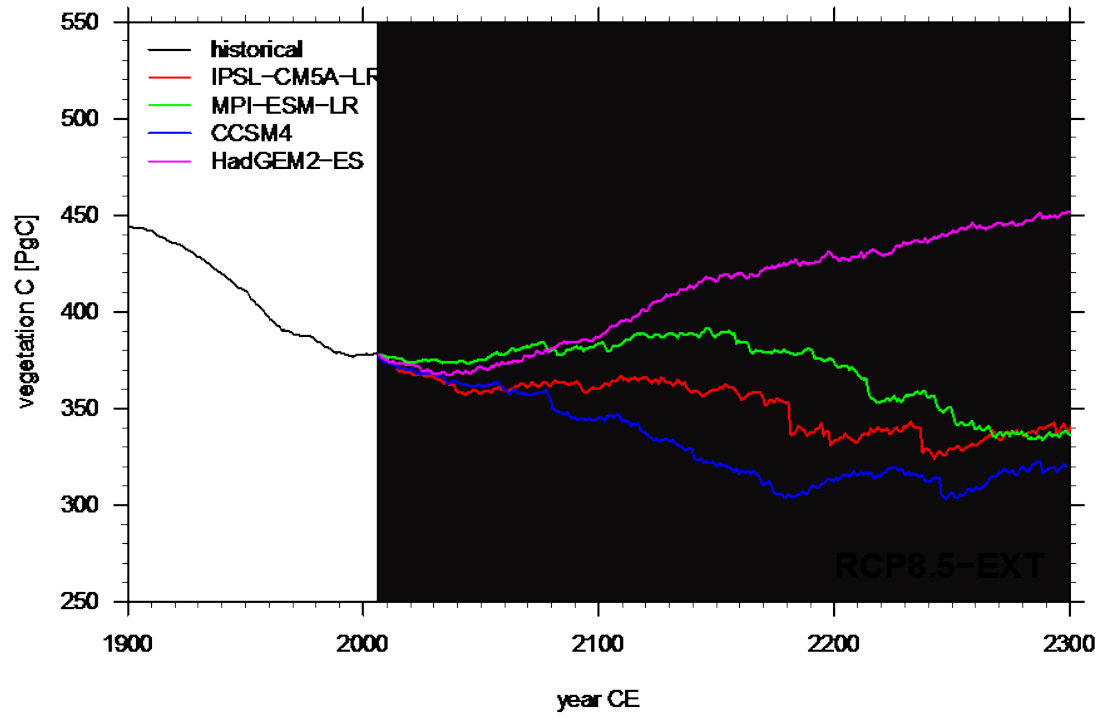

Figure 6 Biomass by climate change pattern from different CMIP5 models over time 